\title{
The sensitivity of snowfall to weather states over Sweden
}

\author{
Lars Norin $^{1}$, Abhay Devasthale ${ }^{1}$, and Tristan S. L'Ecuyer ${ }^{2}$ \\ ${ }^{1}$ Atmospheric Remote Sensing Unit, Research Department, Swedish Meteorological and Hydrological Institute, \\ Norrköping, Sweden \\ ${ }^{2}$ Department of Atmospheric and Oceanic Sciences, University of Wisconsin-Madison, Madison, Wisconsin, USA \\ Correspondence to: Lars Norin (lars.norin@smhi.se)
}

Received: 27 January 2017 - Discussion started: 22 February 2017

Revised: 11 July 2017 - Accepted: 8 August - Published: 5 September 2017

\begin{abstract}
For a high-latitude country like Sweden snowfall is an important contributor to the regional water cycle. Furthermore, snowfall impacts surface properties, affects atmospheric thermodynamics, has implications for traffic and logistics management, disaster preparedness, and also impacts climate through changes in surface albedo and turbulent heat fluxes. For Sweden it has been shown that large-scale atmospheric circulation patterns, or weather states, are important for precipitation variability. Although the link between atmospheric circulation patterns and precipitation has been investigated for rainfall there are no studies focused on the sensitivity of snowfall to weather states over Sweden.

In this work we investigate the response of snowfall to eight selected weather states. These weather states consist of four dominant wind directions together with cyclonic and anticyclonic circulation patterns and enhanced positive and negative phases of the North Atlantic Oscillation. The presented analysis is based on multiple data sources, such as ground-based radar measurements, satellite observations, spatially interpolated in situ observations, and reanalysis data. The data from these sources converge to underline the sensitivity of falling snow over Sweden to the different weather states.

In this paper we examine both average snowfall intensities and snowfall accumulations associated with the different weather states. It is shown that, even though the heaviest snowfall intensities occur during conditions with winds from the south-west, the largest contribution to snowfall accumulation arrives with winds from the south-east. Large differences in snowfall due to variations in the North Atlantic Oscillation are shown as well as a strong effect of cyclonic and anticyclonic circulation patterns. Satellite observations
\end{abstract}

are used to reveal the vertical structures of snowfall during the different weather states.

\section{Introduction}

At high latitudes, solid precipitation is an important contributor to the regional water cycle (Levizzani et al., 2011; Waliser et al., 2011). It impacts surface properties, affects atmospheric thermodynamics, has implications for traffic and logistics management, disaster preparedness, and also impacts climate through changes in surface albedo and turbulent heat fluxes. In a country like Sweden, with strong northsouth gradients in meteorological, topographical, and surface conditions, understanding the response of snowfall to largescale weather states is even more important. Such a characterisation also provides guidance for numerical weather prediction models, which should show a similar response of snow to large-scale weather states, in order to capture snowfall events realistically.

Precipitation variability over Sweden has been investigated in several previous studies (Busuioc et al., 2001; Johansson and Chen, 2003; Hellström, 2005; Gustafsson et al., 2010; Devasthale and Norin, 2014). Since the local circulation patterns (here termed "weather states") often decide the precipitation response, it is important to study dominant weather states and their link to precipitation. The dominant weather states responsible for rainfall and snowfall can be quite different over different regions of Sweden. Furthermore, the dominant weather state may not always explain a significant part of the precipitation variability. Perhaps the most comprehensive evaluation of monthly circulation types over Sweden is done by Chen (2000), Linderson (2001), and 
Busuioc et al. (2001). Among 25 different circulation patterns studied by Chen (2000) over Sweden, four weather states are shown to generally dominate. These are characterised by either cyclonic or anticyclonic conditions or persistent large-scale westerly or south-westerly wind regimes. While the large-scale circulation patterns over the north-east Atlantic favouring westerly and north-westerly winds dominate $35-50 \%$ of the time during the summer months (June through August), the wintertime circulation patterns are often characterised by nearly equal dominance of cyclonic and anticyclonic conditions.

Using data from 33 ground-based stations between the years 1980 and 1990, Busuioc et al. (2001) found that the link between precipitation variability and the dominant circulation patterns can be very complex over Sweden. For example, while the North Atlantic Oscillation (NAO) is the principle mode of sea-level pressure variability during cold months and correlates strongly $(0.86)$ with precipitation, it explained only 32 to $54 \%$ of precipitation variability locally. After NAO, the dipole structure with centres located over eastern Scandinavia and the eastern Atlantic explained about $24 \%$ variability in January and the third mode represented cyclonic/anticyclonic conditions. However, during the summer rainfall months, the cyclonic/anticyclonic conditions dominated circulation types, representing about $37 \%$ variability. Linderson (2001) further observed a robust correspondence between local precipitation and large-scale circulation during winter months over southern parts of Sweden. She showed that over southern Sweden anticyclonic conditions dominated $(16 \%)$ all circulation types.

The link between weather states and precipitation (especially rainfall) during extreme events can be different from that observed during average conditions. For example, Hellström (2005) pointed out the importance of cyclonic and anticyclonic circulations in regulating the summertime extreme precipitation events, while Gustafsson et al. (2010) further argued for the crucial role of continental Europe and the Baltic Sea in controlling the moisture transport during extreme precipitation events. More recently, Thomas and Devasthale (2014) used this weather state classification to investigate temperature and humidity response and pollutant variability over Scandinavia. They showed that the enhanced positive phase of the NAO and south-easterly winds warm the entire troposphere and the surface. These studies form the basis for the investigation and selection of weather states used in the present study. However, it is to be noted that the majority of the studies linking weather states to precipitation over Sweden focus mainly on rainfall and the summer months. Far fewer studies directly address the factors that govern snowfall and its covariability with the other regional impacts of the different wintertime weather states that occur across Sweden and those that do lack sufficient detail to inform forecasts.

The main aim of this work is to exploit the synergy between two remote sensing systems, ground-based weather radar and space-based cloud radar to further document the character of falling snow during each weather state and to quantify the influence of the key meteorological factors that modulate snowfall differences between the different weather states. We seek to answer two specific questions:

1. How does falling snow respond to different atmospheric weather states? The aim here is to investigate to what extent snowfall is sensitive to weather states (different wind directions, mean sea-level pressures (MSLP), and phases of the NAO) and to characterise differences in this dependency between the southern and northern parts of the country. The latter is especially important since the snowfall distribution and frequency is very inhomogeneous meridionally across Sweden, with average snow depths increasing with increasing latitude (Busuioc et al., 2001; Devasthale and Norin, 2014).

2. What are the typical meteorological conditions associated with each weather state and how do they contribute to the observed differences in snowfall between weather states? Here we quantify the extent to which similar covariability between meteorological parameters and snowfall exists across all weather states.

\section{Data sets and weather states}

In this work we have investigated the response of snowfall to eight different weather states. These weather states consist of four dominant wind directions (north-east, north-west, southeast, and south-west) as well as conditions of high and low MSLP and enhanced positive or negative phases of the NAO. To study the response of snowfall to the different weather states we made use of a combination of spatially interpolated in situ observations, reanalyses, ground-based radar measurements, and satellite observations. All dates satisfying any of these conditions were identified in reanalyses. Mean radar-derived surface snowfall intensities and meteorological analyses of surface air temperatures were then composited for these dates. Finally, vertical profiles of reflectivity from satellite observations were extracted to document the vertical structure and implied microphysical properties of snowfall in each weather state.

The following is a description of all data sets used in this study together with a definition of the selected weather states.

\subsection{ERA-Interim reanalysis}

ERA-Interim provides global atmospheric reanalysis, updated continuously since 1979 (Dee et al., 2011). Gridded data products include a large variety of $3 \mathrm{~h}$ surface parameters, describing weather as well as ocean-wave and landsurface conditions, and $6 \mathrm{~h}$ upper-air parameters covering the troposphere and stratosphere. Vertical columns of monthly averages for many atmospheric parameters and other derived fields are also available. Berrisford et al. (2009) provide a detailed description of the ERA-Interim archive. 
The data assimilation system used to produce ERAInterim is based on a 2006 release of the European Centre for Medium-range Weather Forecasting (ECMWF) Integrated Forecast System. The system includes a 4-dimensional variational analysis with a $12 \mathrm{~h}$ analysis window. The spatial resolution of the data set is approximately $80 \mathrm{~km}$ on 60 vertical levels from the surface up to $0.1 \mathrm{hPa}$.

In this study $u$ and $v$ components of winds at $850 \mathrm{hPa}$ were used to identify the dominant weather states. The wind fields have a spatial resolution of about $80 \mathrm{~km}$ and are available every $3 \mathrm{~h}$.

\subsection{Mesan}

To characterise the phase of precipitation $2 \mathrm{~m}$ air temperatures were obtained from Mesan (Häggmark et al., 1997, 2000), a mesoscale analysis system that has been operational at the Swedish Meteorological and Hydrological Institute (SMHI) since 1996. Mesan creates spatially continuous fields of selected meteorological parameters (such as precipitation, temperature, humidity, visibility, wind, and clouds) on a model grid using observations from synoptic stations, automatic stations, satellites, and weather radars. In addition to these observations, a first-guess field from SMHI's operational numerical weather prediction model, HIRLAM (Källén, 1996), is used. The field values of the meteorological parameters are calculated in Mesan using the optimal interpolation technique (Daley, 1993). The Mesan $2 \mathrm{~m}$ temperatures are further adjusted for both the fraction of land in the first-guess field's grid square and for the altitude of the temperature observations.

Mesan covers Scandinavia and the Baltic Sea and has a spatial resolution of $0.1^{\circ} \times 0.1^{\circ}(11 \mathrm{~km} \times 11 \mathrm{~km})$. The temporal resolution is $1 \mathrm{~h}$. Archived data exist from 1998 to the present and are continuously updated.

\subsection{Nordrad}

The meteorological offices in the Nordic countries (Danish Meteorological Institute, Estonian Environment Agency, Finnish Meteorological Institute, Latvian Environment, Geology and Meteorology Agency, Norwegian Meteorological Institute, and SMHI) collaborate by exchanging radar data in real time. The collaboration is called Nordrad (Carlsson, 1995) and consists today of 35 operational weather radars.

The SMHI uses data from all available weather radars within Nordrad to generate composite radar images covering the Nordic countries. These data are corrected for beam blockage (Bech et al., 2003). Non-meteorological echoes, originating for example from ground clutter or clear-air targets, are removed by a satellite-based filter (Michelson, 2006). Furthermore, in order to correct the radar measurements for distance dependence, the radar data are adjusted to precipitation measurements from rain gauges by fitting a second-degree polynomial to the logarithmic gauge-to- radar ratio (Michelson and Koistinen, 2000). The conversion from reflectivity to precipitation rate $R\left(\mathrm{~mm} \mathrm{~h}^{-1}\right)$ is made using the empirical relationship $Z=a R^{b}$ (e.g. Battan, 1973), where $a=200$ and $b=1.5$. For a more detailed description of the radar processing, see e.g. Michelson (2006); Norin et al. (2015).

The quality-adjusted radar data are merged into a precipitation composite, Nordrad, which is generated every $15 \mathrm{~min}$ and has a spatial resolution of $2 \mathrm{~km} \times 2 \mathrm{~km}$. Archived Nordrad composite images exist at the SMHI from 2005 to the present. However, in late 2007 a hardware upgrade was installed at the Swedish weather radars to enable Doppler processing for all scans. In September 2014 a modernisation process began to upgrade all Swedish weather radars to dual polarisation. As a result, the present analysis is restricted to the homogeneous processing period from January 2008 to December 2012.

\subsection{Snowfall product from the CloudSat Cloud Profiling Radar}

CloudSat snowfall estimates were obtained from the Release 04 2C-SNOW-PROFILE (hereafter, 2CSNOW) data product (Wood, 2011; Wood et al., 2013). The product provides vertically resolved snowfall estimates consistent with profiles of W-band $(94 \mathrm{GHz})$ reflectivities measured by CloudSat's Cloud Profiling Radar (CPR). CloudSat observes falling snow between $82^{\circ} \mathrm{N}$ and $82^{\circ} \mathrm{S}$ latitude along a ground track that repeats every 16 days, providing moderately dense spatial sampling at high latitudes relative to more equatorial locations (Kulie et al., 2016; McIlhattan et al., 2017). Snowfall rates are produced at the full $1.7 \mathrm{~km}$ along-track by $1.4 \mathrm{~km}$ cross-track spatial resolution of the CPR. The radar has an intrinsic vertical resolution of $485 \mathrm{~m}$, but measurements are oversampled to yield profiles at an effective vertical resolution of $239 \mathrm{~m}$.

Rather than assuming a fixed relationship between reflectivity and snowfall rate (a so-called $Z-S$ relationship), the 2 CSNOW retrieval algorithm estimates vertical profiles of the probability density functions of snow particle size distribution parameters. Information collected during recent field campaigns are used to supply a priori estimates of the environmental distributions of these parameters as well as snow particle microphysical and scattering properties in the retrieval (Wood et al., 2015). Attenuation and multiplescattering by snow particles are also modelled. A snowfall rate is generated whenever the CloudSat 2C-PRECIPCOLUMN product (Haynes et al., 2009) indicates the presence of frozen precipitation at the surface, defined as a scene with a melted mass fraction of less than $10 \%$. The melted mass fraction is estimated based on the height of the freezing level and a melting model that accounts for the environmental lapse rate below the freezing level derived from ECMWF analyses. 
Ground clutter affects the CPR measurements in the radar range bins nearest the surface so these near-surface bins are not explicitly included in the reflectivity profiles when retrievals are performed, creating what is sometimes called a blind zone. Consequently 2CSNOW estimates the surface snowfall rate as the rate retrieved in the radar bin immediately above the blind zone. Over land, this zone extends about $1 \mathrm{~km}$ above the surface (Smalley et al., 2014). This surface snowfall rate is assigned a confidence value from "none" to "high" depending on the expected performance of the forward model and the reliability of the temperature-based estimate of the precipitation phase, among other factors.

\subsection{Humidity data from the Atmospheric Infrared Sounder}

Humidity profiles from the Atmospheric Infrared Sounder (AIRS) instrument flying on board NASA's Aqua satellite since 2002 are further used to investigate differences in the moisture advection during weather states (Chahine et al., 2006; Susskind et al., 2014; Devasthale et al., 2016). Aqua is part of the A-Train constellation of satellites and travels in front of CloudSat in the same orbit. The retrievals provided in the standard daily gridded Version 6 product (AIRX3STD) at $850 \mathrm{hPa}$ are analysed (Susskind et al., 2014). The estimated accuracy of humidity profiles is $15 \%$ per $2 \mathrm{~km}$. In this study, AIRS provides independent information on the moisture variability during the different weather states.

\subsection{Weather states}

In the present study we have, following Thomas and Devasthale (2014), selected eight different weather states which frequently occur over the Nordic countries. The eight weather states are divided into two groups: wind regimes, consisting of conditions dominated by four wind directions (north-west, north-east, south-east, and south-west), and synoptic states, during which either cyclonic or anticyclonic conditions or enhanced positive or negative phases of the NAO prevailed.

To find days corresponding to the first four weather states the average daily wind speed and wind direction at $850 \mathrm{hPa}$ from the ERA-Interim reanalysis were extracted for an area centred over southern Sweden $\left(55-60^{\circ} \mathrm{N}, 12-20^{\circ} \mathrm{E}\right)$. Based on these daily averages, days during which a particular wind direction prevailed and persisted for at least 3 days were selected in order to capture large-scale precipitation events. Cyclonic and anticyclonic conditions were found in a similar way by analysing the MSLP in the above-mentioned area over southern Sweden. Anticyclonic conditions were identified when the MSLP was more than 1 standard deviation above the mean for 3 consecutive days. If the MSLP was more than 1 standard deviation below the mean, cyclonic conditions prevailed. The NAO indices were obtained from NOAA's Climate Prediction Center website (NOAA, 2016).
Table 1. Number of days during which any of the eight different weather states was found for the period (2008-2012). Note that not all weather states are mutually exclusive.

\begin{tabular}{lrrrrrrrr}
\hline & NE & NW & SE & SW & HI & LO & EN & EP \\
\hline NE & 75 & 0 & 0 & 0 & 38 & 17 & 36 & 20 \\
NW & 0 & 191 & 0 & 0 & 58 & 55 & 68 & 85 \\
SE & 0 & 0 & 77 & 0 & 46 & 7 & 44 & 14 \\
SW & 0 & 0 & 0 & 283 & 53 & 127 & 132 & 67 \\
HI & 38 & 58 & 46 & 53 & 588 & 0 & 211 & 185 \\
LO & 17 & 55 & 7 & 127 & 0 & 624 & 330 & 157 \\
EN & 36 & 68 & 44 & 132 & 211 & 330 & 797 & 0 \\
EP & 20 & 85 & 14 & 67 & 185 & 157 & 0 & 531 \\
\hline
\end{tabular}

Enhanced positive and negative phases of NAO correspond to absolute values of the NAO index exceeding 1 standard deviation during those phases. Enhanced positive or negative NAO conditions were defined as 3 consecutive days with an enhanced positive or negative NAO index.

Table 1 shows the number of days identified for the different weather states during the period January 2008 to December 2012. From the table it is clear that not all weather states are mutually exclusive. For example, it can be seen that more than half of the days characterised by south-easterly winds are also identified as days with high MSLP, whereas days with low MSLP to a large degree coincide with days with enhanced negative NAO.

Representative examples of circulation patterns for the weather states characterised by dominant wind directions are shown in Fig. 1, whereas representative examples of circulation patterns for high and low MSLP together with enhanced positive and negative phases of the NAO are displayed in Fig. 2. In both figures the area over which the wind speed and the MSLP were calculated is depicted by a white rectangle. Because the wind directions are evaluated over southern Sweden the wind directions can be different in the northern part of the country.

\section{Data processing}

The data sets from ERA-Interim and Mesan extend respectively from 1979 and 1998 to the present. Nordrad data are nominally available since 2005 but due to modifications to the Swedish weather radar network, a homogeneous Nordrad data set can only be compiled from 2008 to 2014. Data from CloudSat are available from 2006 to the present. Thus in this study we have restricted the study period to 1 January 2008 to 31 December 2012 when all required data sets are available.

Snowfall products can be generated by combining groundbased radar measurements with near-surface air temperature measurements. While obtaining an accurate and reliable snowfall product is difficult (Harpold et al., 2017), a simple 

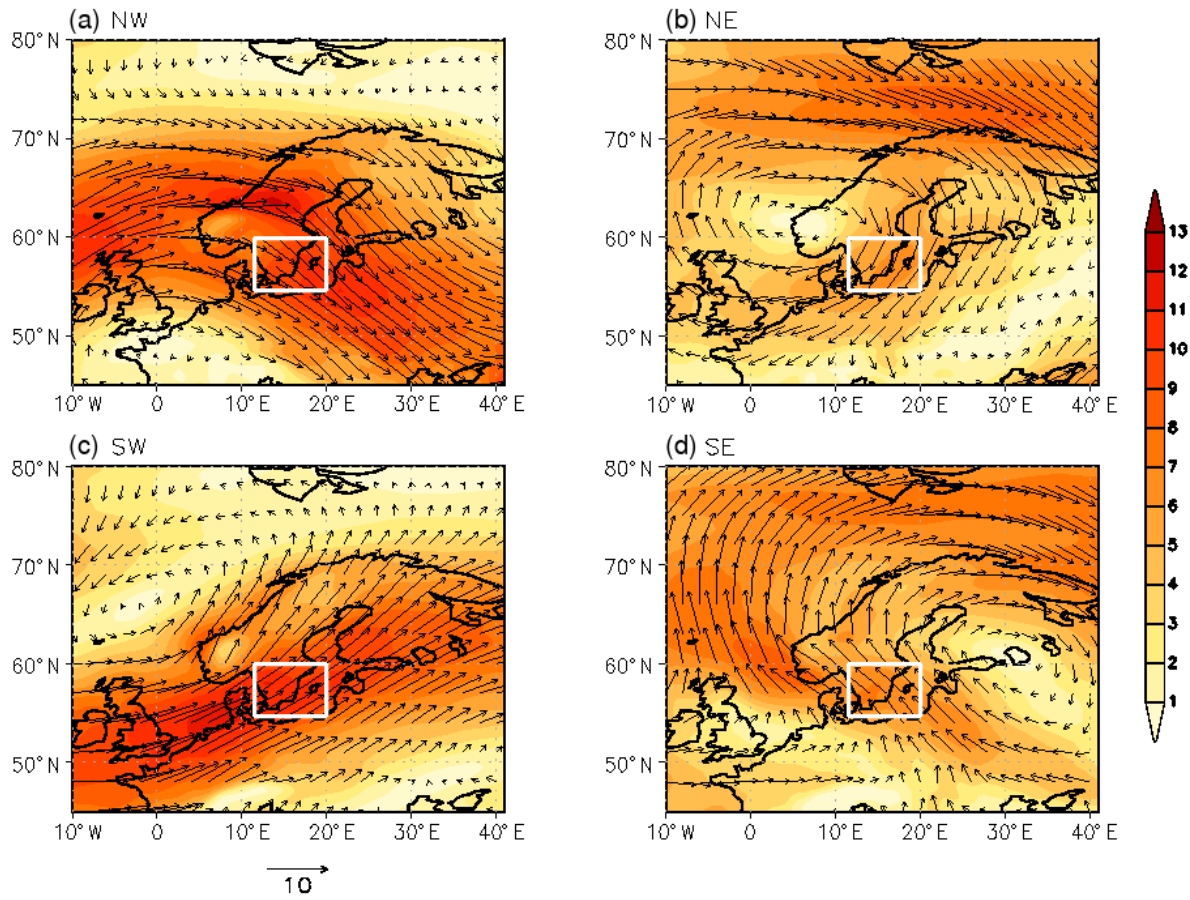

Figure 1. Atmospheric circulation patterns at $850 \mathrm{hPa}$ leading to four persistent wind directions over Sweden. The wind directions were evaluated over the area enclosed by the white rectangle. Panels (a) to (d) show representative examples of circulation patterns resulting in winds from the north-west, north-east, south-west, and south-east. The colour bar indicates wind strength (in $\mathrm{m} \mathrm{s}^{-1}$ ).
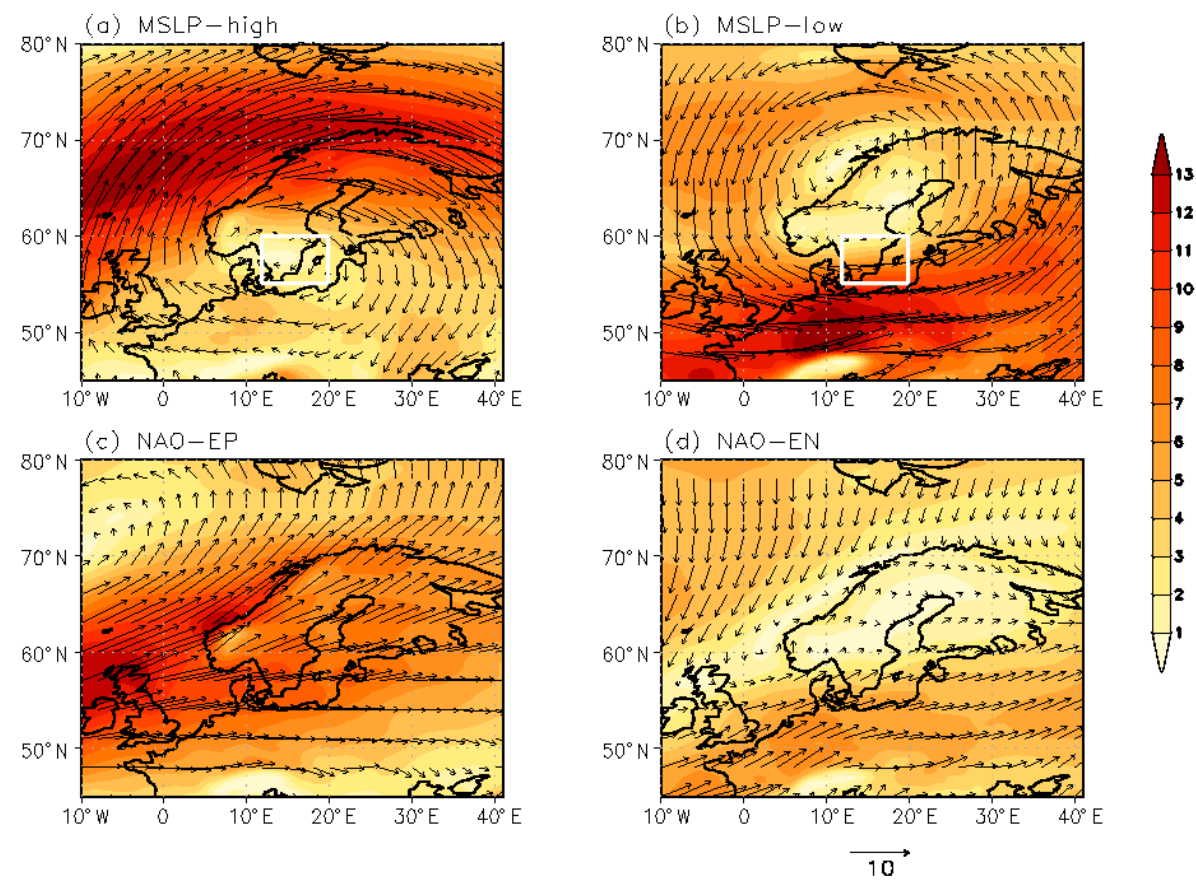

Figure 2. Atmospheric circulation patterns at $850 \mathrm{hPa}$ for four different weather states. Panels (a) and (b) show representative examples of circulation patterns during high and low MSLP conditions (evaluated over the area enclosed by the white rectangle), whereas panels (c) and (d) depict patterns for enhanced positive and negative phases of the NAO. The colour bar shows wind strength (in $\mathrm{ms}^{-1}$ ). 

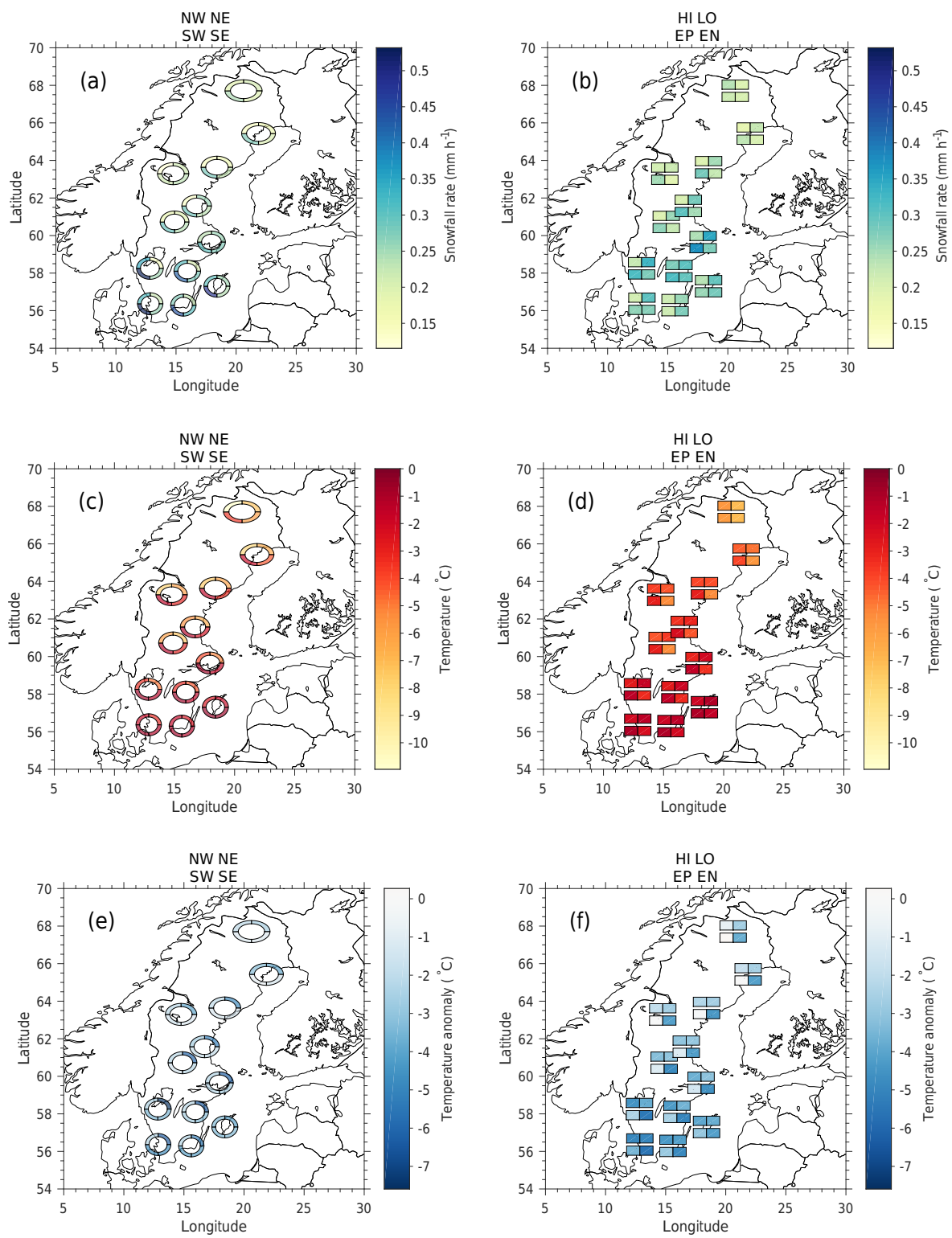

Figure 3. Average snowfall intensities (in $\mathrm{mm} \mathrm{h}^{-1}$ ) observed by the Swedish weather radar network for winds from the north-west, northeast, south-west, and south-east (a) and during high and low MSLP and enhanced positive and negative NAO conditions (b). Average $2 \mathrm{~m}$ temperatures (in ${ }^{\circ} \mathrm{C}$ ), obtained from the mesoscale analysis system Mesan, for winds from the north-west, north-east, south-west, and southeast (c) and during high and low MSLP and enhanced positive and negative NAO conditions (d). Average temperature anomalies (in ${ }^{\circ} \mathrm{C}$ ), obtained from the mesoscale analysis system Mesan, for winds from the north-west, north-east, south-west, and south-east (e) and during high and low MSLP and enhanced positive and negative NAO conditions (f). The coloured rings in panels (a), (c) and (e) correspond to the radar coverage area used in the analysis.

but robust snowfall product is sufficient for the purpose of this study.

As described in Norin et al. (2015), a simple but robust radar-based snowfall product can be generated by combining Nordrad's precipitation composite with $2 \mathrm{~m}$ temperatures from Mesan. For every Nordrad composite image the $2 \mathrm{~m}$ temperature field from Mesan that was nearest in time and space was used to identify frozen precipitation. If the $2 \mathrm{~m}$ temperature was below freezing $\left(0^{\circ} \mathrm{C}\right)$ the corresponding precipitation from Nordrad was classified as snow, otherwise as rain. In this work we have used snowfall estimates from the Nordrad composites, but in order to provide a uniformly calibrated data set as well as to have full knowledge of the measurements we have only selected radar data originating from areas covered by Swedish radars. 

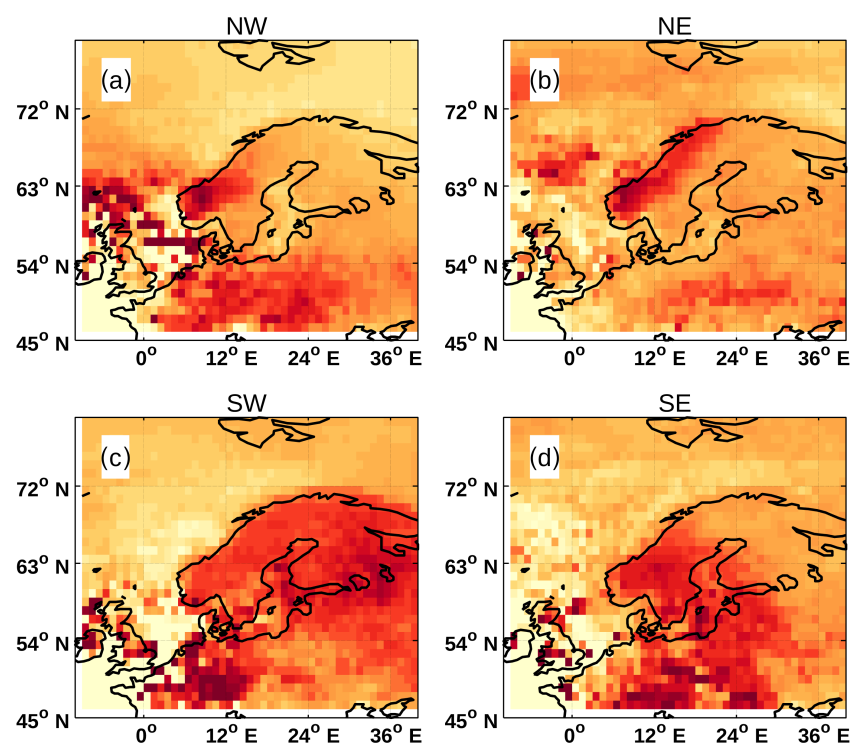

0.5

1

1.5

Specific humidity $\left(\mathrm{g} \mathrm{kg}^{-1}\right)$

Figure 4. Average values of specific humidity, observed by AIRS at $850 \mathrm{hPa}$. Panel (a) shows the specific humidity for atmospheric conditions dominated by winds from the north-west. In panels (b) to (d) the winds are from the north-east, south-west, and south-east.

Comparing ground-based radar measurements of snowfall intensities to CloudSat snowfall measurements, Norin et al. (2015) found that Nordrad snowfall estimates are optimal at distances between 46 and $82 \mathrm{~km}$ from a Swedish radar station. Outside this range the disagreements were larger due to a combination of different reasons. The sensitivity of the ground-based radars decreases for increasing distances, making it more difficult to detect light snowfall at large distances. At large distances Nordrad also systematically overshoots low-level precipitating systems. This leads to an underestimation of Nordrad's measured snowfall rates and occasionally to Nordrad missing precipitation altogether. Close to the radar stations Nordrad detects non-precipitating, lowintensity echoes that can be misclassified as light snowfall.

Snowfall intensities from Nordrad were therefore selected within the optimal distance range from the 12 Swedish weather radar stations together with the corresponding $2 \mathrm{~m}$ temperatures from Mesan, for each of the eight identified weather states. The average number of radar cells within the optimal measurement zone for any radar is approximately 3620, while Mesan has approximately 120 data grid boxes covering the same area.

Average intensity of falling snow and the corresponding average $2 \mathrm{~m}$ temperature were calculated for measurements containing precipitation for all days assigned to each weather state. Corresponding temperature anomalies were defined relative to the daily average $2 \mathrm{~m}$ temperatures from Mesan for all regions within the optimum distance over the period from 2008 to 2012.

CloudSat samples data every $1.4 \mathrm{~km}$ and passes over Sweden twice each day. The CloudSat satellite has been operational since 2006, but in April 2011, the satellite experienced a battery anomaly that caused a 10-month gap in the observations. Measurements resumed in February 2012 but the satellite has only operated during the daytime portion of its orbit since that time. In this study, all available ascending and descending passes of CloudSat from 1 January 2006 to 31 December 2012 in the latitude band between 54 and $70^{\circ} \mathrm{N}$ were used (excluding the summer months, June to September, in which no snowfall was observed). To ensure high quality, only CloudSat snowfall retrievals with a confidence flag corresponding to "moderate" or "high" were used in the analysis, yielding between 0 and 1007 observed snowfall profiles per day. CloudSat vertical snowfall profiles together with the estimated surface height over Sweden were composited for each weather state to characterise the vertical structure of snowfall in each regime. Due to the lower temporal resolution of CloudSat, average vertical profiles were calculated using data from the entire country to obtain sufficient amounts of data for the different weather states. Snowfall intensities below $1250 \mathrm{~m}$ above the surface were excluded to avoid CloudSat's blind zone.

The humidity profiles at $850 \mathrm{hPa}$ available at the $1^{\circ} \times 1^{\circ}$ resolution from the AIRX3STD were analysed in the same way as the surface temperature data from MESAN, i.e. by taking into account the only those cases where surface temperatures (also derived from AIRS for the sake of consistency) were colder than $0^{\circ} \mathrm{C}$. The data from the ascending passes of AIRS were analysed.

\section{Results and discussion}

The response of snowfall to the eight selected weather states were examined using the snowfall products from Nordrad and CloudSat, together with temperature observations from Mesan and measurements of specific humidity from AIRS. Below, the results for the two different groups of weather states are presented and the implications for snowfall accumulations are discussed.

\subsection{Snowfall during dominant wind regimes}

Average snowfall intensity for the weather states characterised by the four dominant wind directions (north-west, north-east, south-west, and south-east, as illustrated in Fig. 1) from all of Sweden's 12 weather radars are shown in Fig. 3a. In general the average snowfall intensities are seen to decrease with increasing latitude. The smallest average snowfall intensities, below $0.2 \mathrm{~mm} \mathrm{~h}^{-1}$, are seen to occur for winds from the south-east at northern radar stations (above $60^{\circ} \mathrm{N}$ ). It is also found that the largest average snowfall intensities 
occur when winds originate from the south-west. This is valid for all radar stations, except for one radar located in the north-western region which is slightly more influenced by north-westerly frontal systems arriving from the Norwegian Sea. For the southernmost radar stations (below $59^{\circ} \mathrm{N}$ ), where this effect is most evident, average snowfall intensities are near $0.5 \mathrm{~mm} \mathrm{~h}^{-1}$.

The corresponding $2 \mathrm{~m}$ temperatures, shown in Fig. $3 \mathrm{c}$, reveal that the most intense snowfall occurs at warmer temperatures, ranging from approximately -1 to $-4{ }^{\circ} \mathrm{C}$, whereas the lightest snowfall intensities correspond to colder temperatures, between -6 and $-11{ }^{\circ} \mathrm{C}$. For northerly winds the snowfall intensities are similar, around $0.15-0.25 \mathrm{~mm} \mathrm{~h}^{-1}$. However, snowfall intensities are slightly larger for winds from the north-west for the southernmost radar stations (below $59^{\circ} \mathrm{N}$ ). The corresponding $2 \mathrm{~m}$ temperatures are on average $1-3^{\circ} \mathrm{C}$ warmer compared to the north-easterly wind regime. Figure $3 \mathrm{e}$ shows that temperature anomalies (relative the daily average temperature, see Sect. 3) during snowfall are, in general, largest for the southernmost stations, for all wind directions. However, the largest temperature anomalies for all station occur for winds from the north-east, ranging from -2 to $-7^{\circ} \mathrm{C}$, while the smallest temperature anomalies $\left(0\right.$ to $\left.-3^{\circ} \mathrm{C}\right)$ occur for winds from the south-east.

Average values of specific humidity, observed by AIRS, are shown in Fig. 4. In agreement with the snowfall observations it is seen that winds from the south-west advect sufficient moisture over all of Sweden, which in combination with warm temperatures leads to large snowfall intensities. With winds arriving from the south-east, moist air originating from continental Europe passes over the southern and central parts of Sweden. Together with warm temperatures this leads to increased snowfall intensities. On the other hand, this moist air does not reach the northern parts of the country and this lack of moisture in combination with cold temperatures results in small snowfall intensities. For northerly winds moist air from the Atlantic is blocked by the mountains on the border to Norway and the result is moderate snowfall over Sweden. Anomalies of specific humidity (relative the daily average specific humidity, see Sect. 3) are presented in Fig. 5. The anomalies show that unusually moist air covers Sweden during south-westerly winds, while the opposite occurs with winds from the north. With winds from the south-east, southern Sweden receives moist air, while the air in the northern part of the country is drier than usual.

Figure 6 shows the vertical structure of snowfall, as observed by CloudSat, for the four weather states characterised by dominant wind directions. Mean snowfall rates as a function of altitude are shown together with 2-D histograms of snowfall intensities and altitudes. In addition, the altitudes at which 50 and $95 \%$ of the snowfall rates were observed are displayed. It is seen that the largest mean near-surface snowfall rates, above $0.2 \mathrm{mmh}^{-1}$, occur during westerly wind regimes. These snow events are characterised by deeper snow columns and stronger vertical intensity gradients that may be
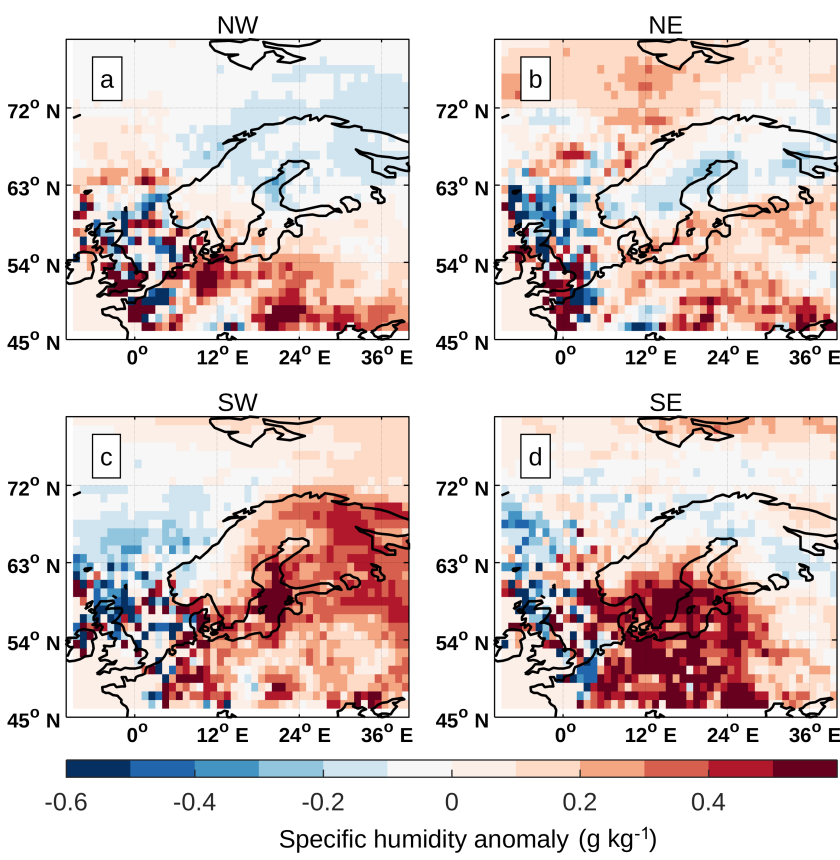

Figure 5. Anomalies of specific humidity, observed by AIRS at $850 \mathrm{hPa}$. Panel (a) shows anomalies in the specific humidity for atmospheric conditions dominated by winds from the north-west. In panels (b) to (d) the winds are from the north-east, south-west, and south-east.

indicative of enhanced aggregation processes relative to easterly snow events. The smallest mean near-surface snowfall intensity, below $0.1 \mathrm{~mm} \mathrm{~h}^{-1}$, occurs during winds from the south-east, consistent with the observations from the groundbased radars. It is also interesting to note that the mean snowfall intensity (approximately $0.1 \mathrm{~mm} \mathrm{~h}^{-1}$ ) from the ground up to $5 \mathrm{~km}$ above the surface in north-easterly regimes indicates an absence of aggregation in the prevailing colder, drier conditions. Near the surface, the distribution of snowfall intensities peaks around $0.5 \mathrm{~mm} \mathrm{~h}^{-1}$ when winds are from the south-west. For winds from the east, the distribution of snowfall rates peaks at a much lower intensity, below $0.01 \mathrm{~mm} \mathrm{~h}^{-1}$. Since the histograms of the vertical snowfall structure were obtained using data from the entire country (see Sect. 3) the spatial information in Fig. 6 has been lost. However, when we compared vertical profiles from the northern and the southern parts of the country, no noticeable difference in the vertical structure could be found.

The different response of the snowfall intensities to these weather states can be understood by examining the circulation patterns in Fig. 1. Winds from the south-west originate from the Atlantic and the North Sea, bringing moist, warm air over Sweden, resulting in heavy snowfall once the temperature falls and sustains below $0{ }^{\circ} \mathrm{C}$. Winds from the northwest also originate from the Atlantic but pass over the mountainous border to Norway before arriving in Sweden, thereby bringing less snow at slightly colder temperatures compared 

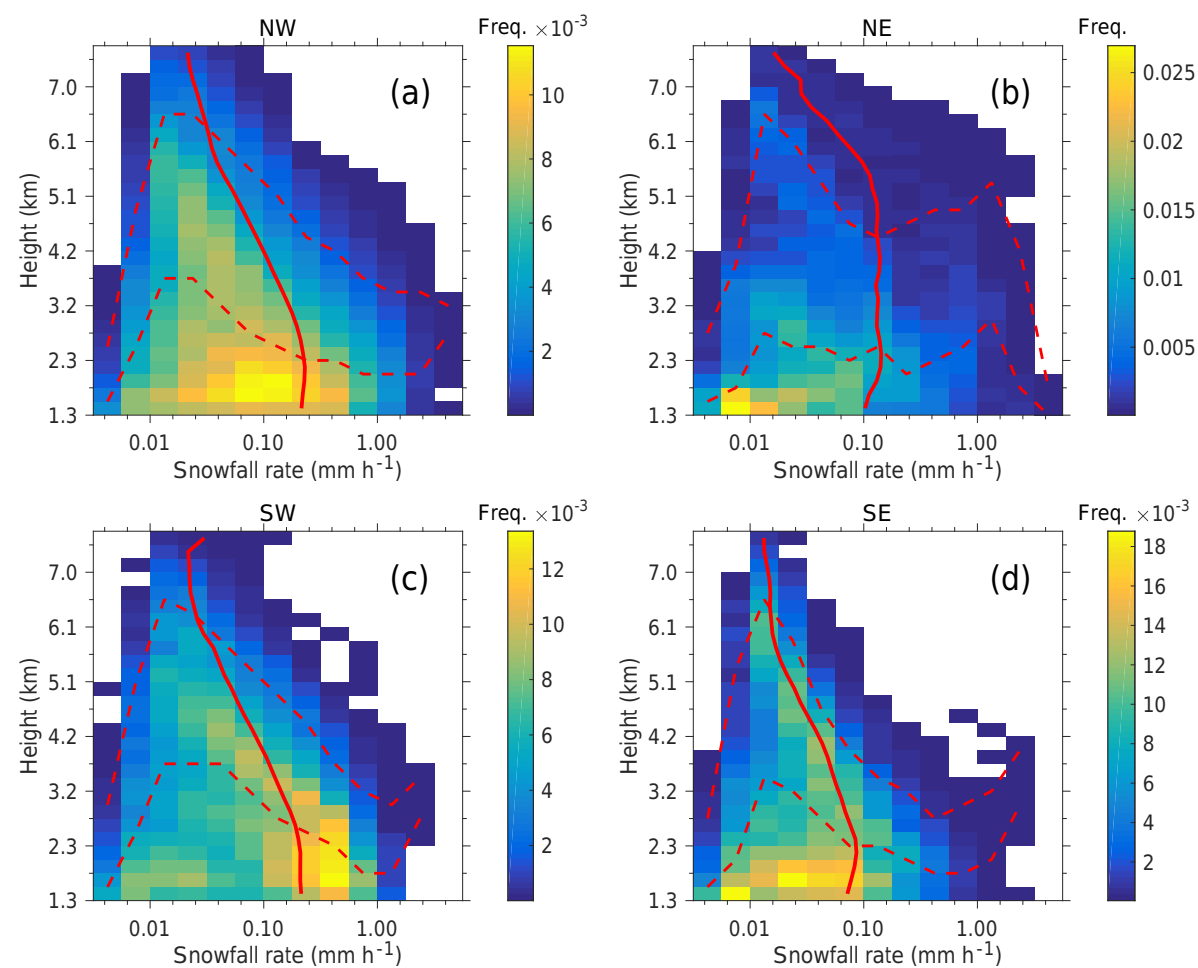

Figure 6. Histograms showing the relative frequency of snowfall rates as a function of altitude above the surface, using data from CloudSat. The different panels show the vertical structure of snowfall for weather states dominated by different wind directions (north-west, north-east, south-west, and south-east). The red solid lines show the mean snowfall rates as a function of altitude. The two red dashed lines show the altitudes where 50 and $95 \%$ of the snowfall occurred, as a function of snowfall intensity.

to south-westerly winds. These north-westerly winds have the second-largest influence on the central Swedish regions (after south-westerly winds). Winds from the north-east, on the other hand, arrive from the Norwegian Sea and Barents Sea and bring relatively colder air and less moisture, have the second-largest impact (after south-westerly winds) on the northernmost Swedish regions. Finally, south-easterly winds originating from continental Europe pick up moisture from the southern Baltic Sea, resulting in moderate snowfall intensities over southern Sweden. Their influence on the northern parts of the country is minimal. This is mainly due to the fact that south-easterly frontal systems dry up before reaching the northernmost parts of Sweden. Furthermore, the Bay of Bothnia is frozen and covered by sea ice during core winter months closing the moisture source in the Baltic Sea. These results underline the varied meridional nature of the response of snowfall to dominant wind directions.

\subsection{Snowfall during different synoptic states}

The principles behind the results for the dominant wind regimes are also manifested in the observed sensitivity of snowfall to MSLP and enhanced positive or negative NAO index.
Figure $3 b$ shows that for the weather state characterised by anticyclonic conditions (high MSLP), corresponding to an atmospheric blocking-like circulation pattern that stagnates over the entire southern Scandinavia, average snowfall intensities are similar for all radar stations, around 0.2$0.25 \mathrm{~mm} \mathrm{~h}^{-1}$. Temperatures range between -6 and $-2{ }^{\circ} \mathrm{C}$ with the colder temperatures occurring at the northern stations (Fig. 3d, f). When cyclonic conditions prevail (low MSLP) the snowfall intensities are higher, as expected, ranging from 0.25 to $0.40 \mathrm{~mm} \mathrm{~h}^{-1}$ for the southern radar stations. On the other hand, at the northern stations snowfall rates are $0.2-0.3 \mathrm{~mm} \mathrm{~h}^{-1}$ for both cyclonic and anticyclonic regimes. The average values for the specific humidity, as observed by AIRS, for high and low MSLP are presented in Fig. 7a and $b$. The corresponding anomalies are shown in Fig. 8. It is seen that during high MSLP the air is more humid than for conditions with low MSLP. This is in contrast to the observations of snowfall intensities. To understand this apparent paradox we must examine the vertical structure of snowfall.

Figure $9 \mathrm{a}$ and $\mathrm{b}$ show the vertical structure of snowfall during high and low MSLP, respectively, as observed by CloudSat. It can be seen that the mean snowfall intensity near the surface is around $0.2 \mathrm{~mm} \mathrm{~h}^{-1}$ during both weather states, agreeing with ground-based observations (see Fig. 3b). CloudSat observations suggest, however, that 

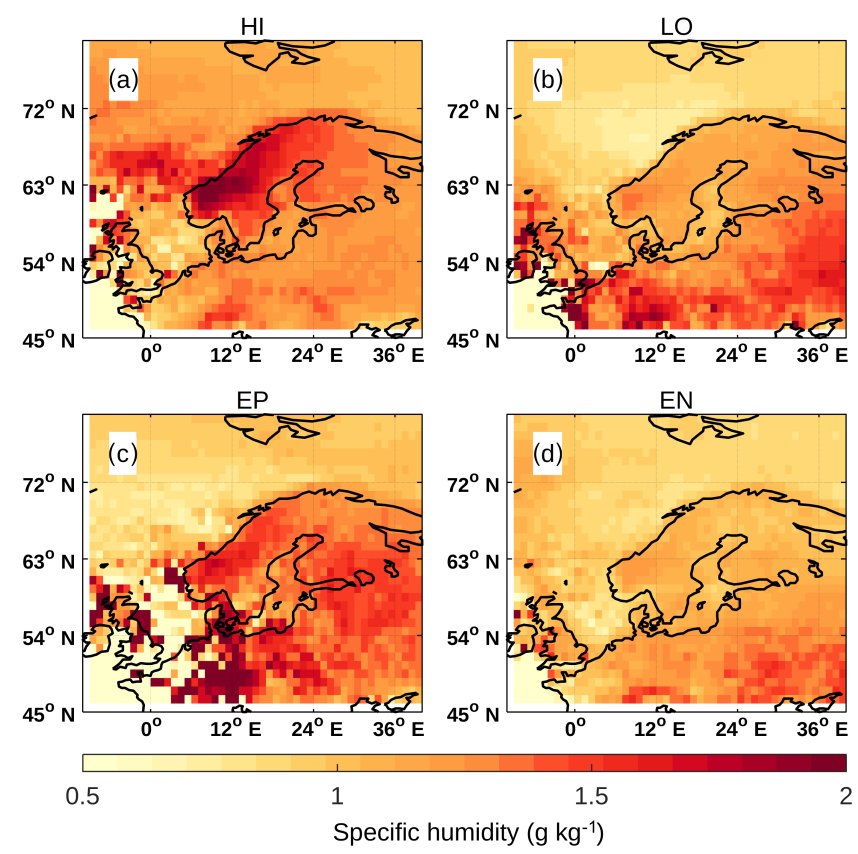

Figure 7. Average values of specific humidity, observed by AIRS at $850 \mathrm{hPa}$. Panels (a) and (b) show average values of the specific humidity for high and low MSLP, while panels (c) and (d) show the corresponding variable for enhanced positive and negative phases of the NAO.

more vertically developed snowfall events occur predominantly during anticyclonic conditions. When MSLP is high, snowfall rates are confined around $0.1-0.2 \mathrm{~mm} \mathrm{~h}^{-1}$ at all heights from the surface up to $3 \mathrm{~km}$, whereas the vertical distributions of snowfall during low MSLP events are more widespread, ranging from 0.01 to $0.5 \mathrm{~mm} \mathrm{~h}^{-1}$.

It can now be explained why the specific humidity is higher during anticyclonic conditions, while at the same time the average surface snowfall rates are similar. Figure 2a shows that during high MSLP conditions, anticyclonic winds coming from central Europe further pick up moisture from the North Sea before releasing precipitation over western coast of Norway and southern parts of Sweden. This leads to increase in specific humidity over these regions (see Figs. 7a and 8a). These snowfall events, whenever they do occur, also seem to be well vertically developed as evident in Fig. 9a. However, during low MSLP conditions, the location of low pressure (Fig. 2b) is such that more northerly, colder winds result in lower specific humidity anomalies (Fig. 8b). Notice however that over the southernmost tip of Sweden, humidity anomalies are slightly positive during low MSLP conditions due to warmer south-westerly winds. Since the centre of the low pressure is slightly northward (compared to the centre of the high pressure), the occurrence of snowfall events with differing intensities, over northern and southern regions of Sweden leads to more broader vertical distribution of snowfall as observed by CloudSat (Fig. 9b).
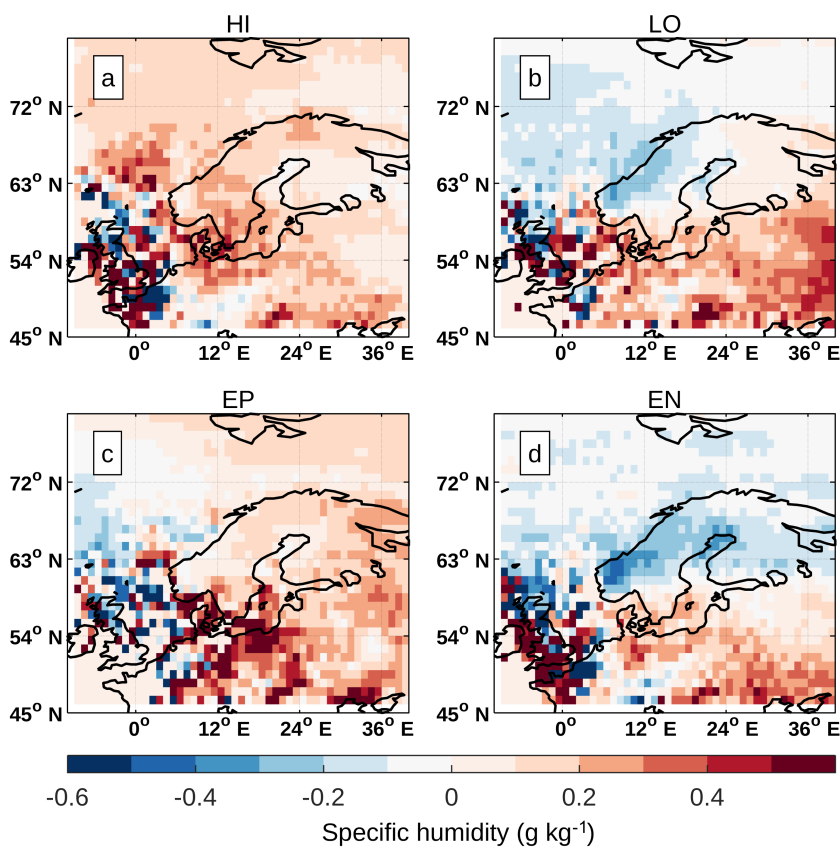

Figure 8. Anomalies of specific humidity, observed by AIRS at $850 \mathrm{hPa}$. Panels (a) and (b) show anomalies in the specific humidity for high and low MSLP, while panels (c) and (d) show the corresponding variable for enhanced positive and negative phases of the NAO.

The apparent insensitivity of snowfall to change in MSLP over the northern parts of Sweden can be understood by noting that during anticyclonic conditions these areas receive similar amount of average snowfall from winds carrying moisture from the northern part of the Norwegian Sea. Very low differences in average temperatures over the northern regions during anticyclonic and cyclonic conditions are further observed (Fig. 3d). At $850 \mathrm{hPa}$ the air is more humid for high MSLP leading to the observed differences in the vertical structure of snowfall. However, even though the distribution of snowfall intensities are very different during these weather states the average snowfall rates are similar at the surface.

Ground-based observations of snowfall intensities during weather states with enhanced positive NAO indices, shown in Fig. $3 b$, range between 0.20 and $0.35 \mathrm{~mm} \mathrm{~h}^{-1}$ and are quite similar to those observed during enhanced negative NAO phase. Except for the south-eastern coast, snowfall intensities during positive NAO indices are slightly larger. The corresponding average temperatures are shown in Fig. 3d. It is seen that temperatures decrease with increasing latitude but also that temperatures are $1-3^{\circ} \mathrm{C}$ colder for enhanced negative phase of the NAO. The average values for the specific humidity are depicted in Fig. 7c and d. During enhanced positive NAO conditions the air is more humid compared to conditions of enhanced negative NAO. 

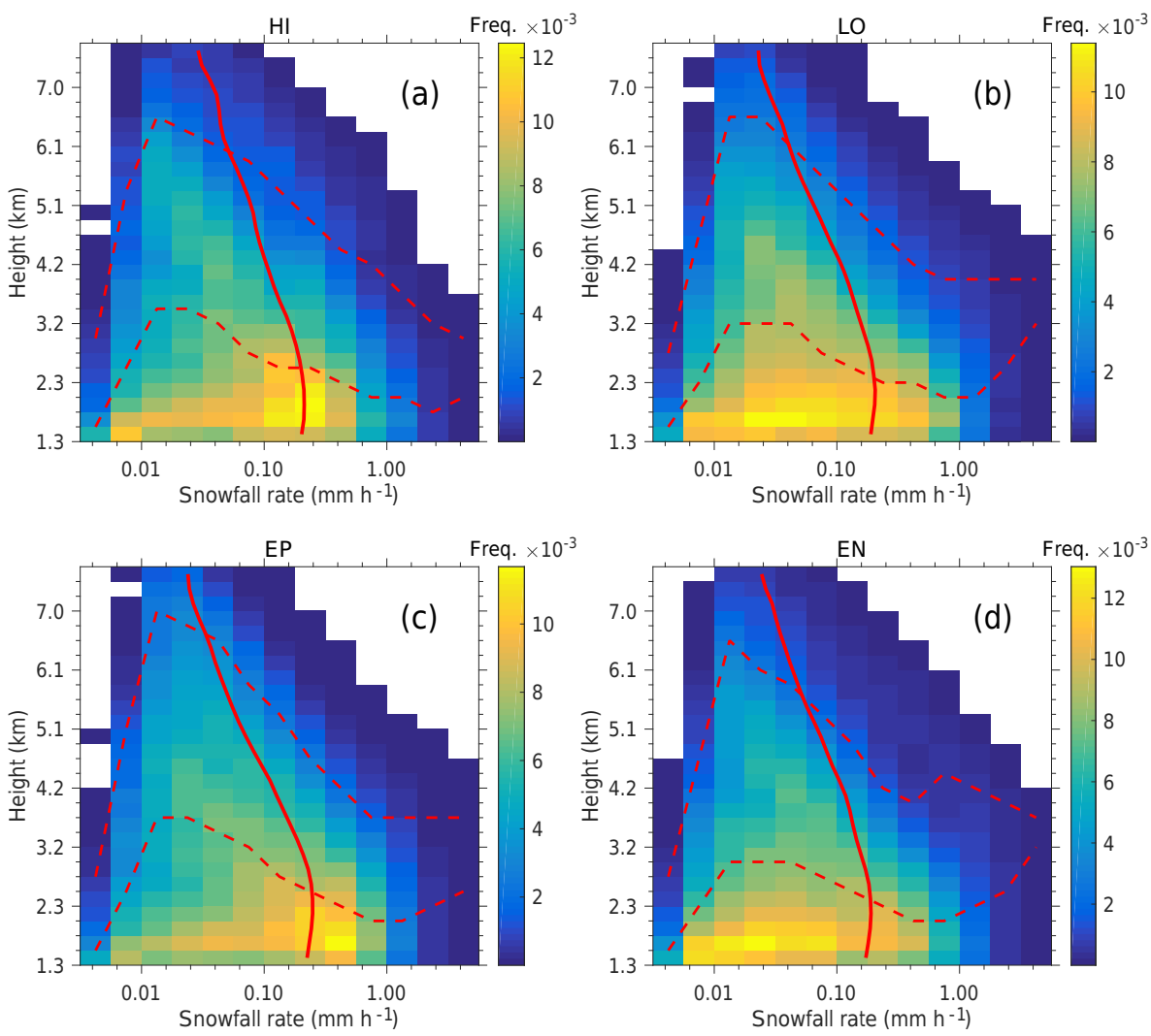

Figure 9. Histograms showing the relative frequency of snowfall rates as a function of altitude above the surface, using data from CloudSat. The different panels show the vertical structure of snowfall for weather states with high and low MSLP (a, b), and enhanced positive and negative NAO indices (c, d). The red solid line shows the mean snowfall rate as a function of altitude. The two red dashed lines show the altitudes where 50 and $95 \%$ of the snowfall occurred, as a function of snowfall intensity.

By examining CloudSat's observations of the vertical structure of snowfall during these weather states, shown in Fig. $9 \mathrm{c}$ and $\mathrm{d}$, it can be seen that the mean snowfall rate near the surface is slightly higher for the enhanced positive NAO phase, near $0.25 \mathrm{~mm} \mathrm{~h}^{-1}$, compared to the enhanced negative NAO phase, $0.2 \mathrm{~mm} \mathrm{~h}^{-1}$. The median heights of the snowfall intensities are similar for both conditions. A more obvious difference can be seen in the distribution of the snowfall intensities. For enhanced positive NAO phase the snowfall distribution peaks around $0.4 \mathrm{~mm} \mathrm{~h}^{-1}$ for heights from the surface up to $2 \mathrm{~km}$, whereas the distribution of snowfall intensities during enhanced negative NAO phase is more widespread, dominated by snowfall intensities from 0.005 to $0.1 \mathrm{mmh}^{-1}$.

The similarity in snowfall intensities during enhanced negative and enhanced positive NAO phases can be explained by temperature anomalies (Fig. 3f) and circulation patterns (Fig. 2). During the enhanced positive NAO phase, only the persistent south-westerly winds can bring sufficient moisture to colder northern parts of Sweden to create snowfall events with average intensities similar to those during the negative phase of NAO. While in the case of enhanced negative NAO phase over the southern parts of country, the circulation pat- tern favours conditions wherein southerly moist winds are confronted by colder and drier northerly winds (Fig. 8d), resulting in snowfall events with average intensities similar to those during the enhanced positive NAO phase. These results underline the complex interplay between circulation patterns and snowfall by affecting moisture transport and meridional temperature gradients.

\subsection{Implications for snowfall accumulations}

The relative strengths of the snowfall intensities for the different weather states are shown in Fig. 10a and b. In order to more easily compare the snowfall intensities they have been normalised in Fig. 10a and $\mathrm{b}$ so that the sum of the snowfall intensities is equal to one for each of the different groups of weather states (wind directions, MSPL, and NAO). In Fig. 10a it can be seen that the highest snowfall intensities occur for winds from the south-west for almost all stations in Sweden, which is a result of the warm temperatures and moist air that characterises this weather state. The other dominant wind directions all lead to similar snowfall intensities, albeit due to different reasons which were discussed in the preceding sections. 

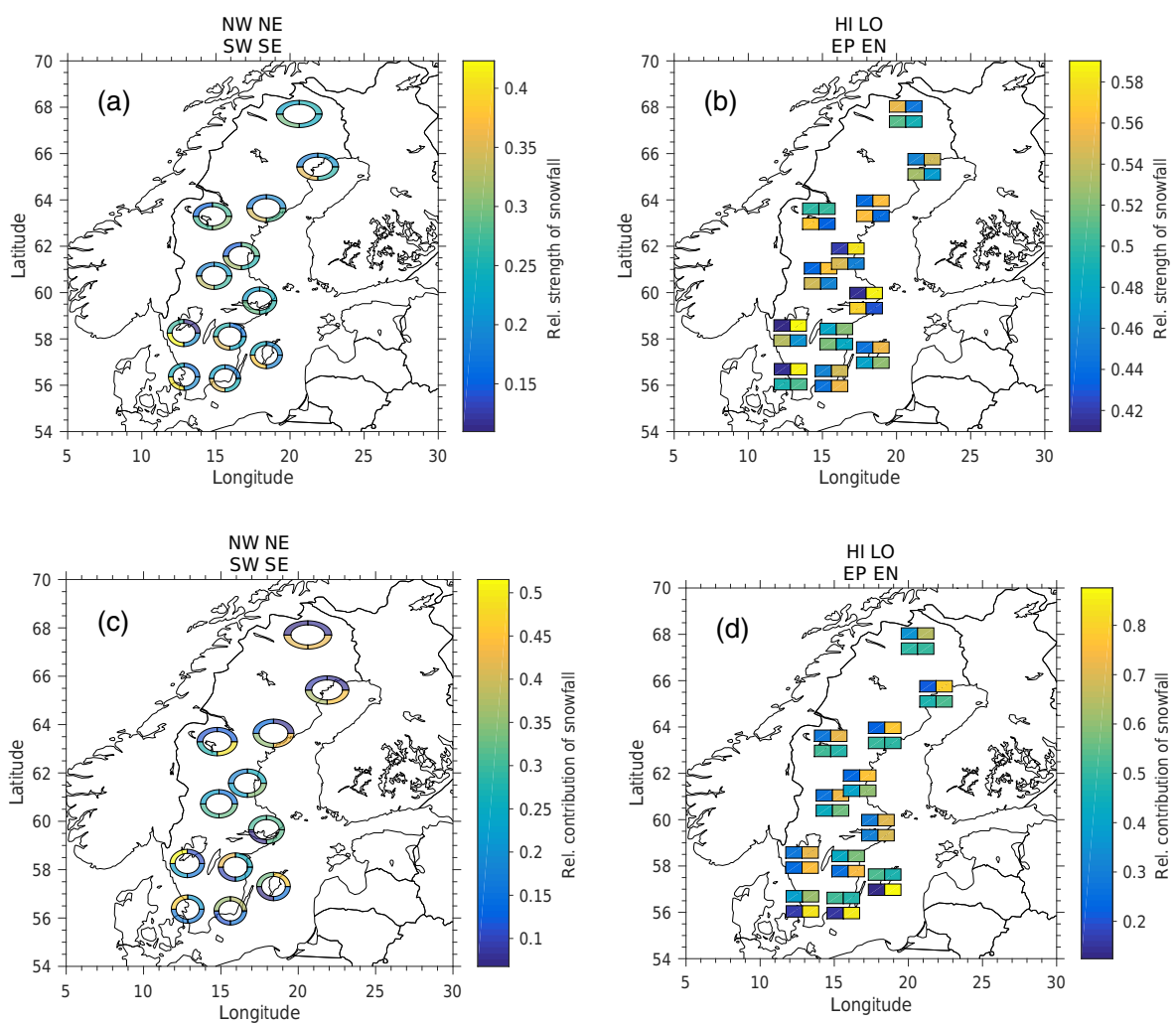

Figure 10. Relative strength of snowfall intensities for winds from the north-west, north-east, south-west, and south-east (a). For every radar station the sum of the relative strength from the four wind directions is equal to one. Relative strength of snowfall intensities during high and low MSLP and enhanced positive and negative NAO conditions (b). Here the sum of the relative strength during high and low MSLP for every station is equal to one as well as the sum of the relative strength during enhanced positive and negative NAO conditions. Relative contribution of total snowfall for winds from the north-west, north-east, south-west, and south-east (c). The sum for every radar station is equal to one. Relative contribution of total snowfall during high and low MSLP and enhanced positive and negative NAO conditions (d). The sum of the relative contribution during high and low MSLP for every station is equal to one and the sum of the relative contribution during enhanced positive and negative NAO conditions is equal to one. The coloured rings in panels (a) and (c) correspond to the radar coverage area used in the analysis.

From the presented analysis no quantitative statement can be made for snowfall accumulation. However, the relative contribution of the different weather states to the total snowfall amount can be estimated by multiplying the average snowfall intensities with the number of days for each weather state. Even though snowfall intensities are highest for winds from the south-west, this weather state does not contribute most to the total snowfall amount. The relative contribution to snowfall accumulation for weather states characterised by dominant wind directions are shown in Fig. 10c. Here it is seen that for southern radar stations easterly winds lead to the largest amount of snow, whereas for northern stations winds from the north-west lead to the largest snowfall accumulation. These results reflect the frequency with which snowfall occurs during the different wind regimes. For example, even though south-westerly winds are the most common wind direction in Sweden, they are usually accompanied by warm temperatures. Hence precipitation normally falls as rain during this weather state but if temperatures happen to be below $0{ }^{\circ} \mathrm{C}$, the snowfall intensities become large. On the other hand, during easterly winds temperatures are more often freezing and these weather states therefore contribute most to the total accumulation of snow.

For the other weather states (high and low MSLP and enhanced positive or negative NAO indices) the relative strength of the snowfall intensities are shown in Fig. 10b. The absolute differences in snowfall intensities are smaller for these weather states compared to those characterised by the dominant wind directions. However, it is seen that higher snowfall intensities occur for low MSLP for all of Sweden (except at the very north), while snowfall intensities are slightly higher for enhanced positive NAO for almost the entire country, except for the southernmost part.

For high and low MSLP it is clear that the contribution to total snowfall accumulation is larger for weather states with low MSLP for all stations. This is partly a reflection of the higher snowfall intensities associated with low MSLP but also due to the higher frequency with which it snows during 
these conditions. For enhanced positive and negative NAO indices it is clear that in southern Sweden the contribution to total snow accumulation is dominated by conditions with enhanced negative NAO. This is because snowfall is relatively uncommon during weather states characterised by enhanced positive NAO, due to the warm temperatures. For northern Sweden both weather states contribute with approximately the same amount.

\section{Conclusions}

In this work we have examined the sensitivity of snowfall to eight different atmospheric circulation patterns, or weather states, commonly occurring over Sweden. The circulation patterns include four dominant wind directions, high and low MSLP, and enhanced positive and negative NAO indices. To this end we have used a combination of different data sources: spatially interpolated in situ observations, ground-based radar data, satellite measurements, and reanalyses products.

It was found that falling snow over Sweden is indeed sensitive to different atmospheric weather states. A clear variation in average snowfall intensity was observed, depending on circulation pattern but also depending on latitude. Snowfall over southern Sweden responds to different weather states in a different way compared to over the northern parts of the country. The largest snowfall intensities were observed for south-westerly winds, which bring warm, moist air from the Atlantic over the entire country. The smallest average snowfall rates for northern Sweden were observed during southeasterly winds, while the southern parts of the country received the smallest snowfall rates north-easterly winds.

Using satellite observations the vertical snowfall structure of snowfall were examined. Clear differences between the various circulation patterns could be observed. During easterly winds snowfall was seen to be much shallower compared to snowfall during westerly winds. During high MSLP and positive phases of the NAO, snowfall tended to be concentrated to larger intensities compared to conditions with low MSLP or negative phases of the NAO.

Snowfall accumulations depend on the observed snowfall rates but also on the frequency with which the weather states occur. It was found that easterly winds contribute most to snowfall accumulation over southern Sweden, whereas westerly winds bring the largest snow amounts to the northern parts of the country. Further, low MSLP and negative phases of the NAO contribute more to snowfall accumulation than high MSLP and positive phases of the NAO.

These results indicate a complex interplay between circulation patterns, heat and moisture transport, and snowfall and underlines the varied meridional nature of this interplay. The study also demonstrates the advantage of the synergetic use of different observing systems to investigate snowfall variability. This study was performed over Sweden but a similar study could easily be performed for other regions that have long-term radar observations available.

Data availability. ERA-Interim data can be accessed from the website of the ECMWF, http://apps.ecmwf.int/datasets/. Nordrad data for research are available on request from SMHI. Composites based only on Swedish radars, very similar to Nordrad, are available from http://opendata-catalog.smhi.se/explore/ where Mesan data can also be downloaded. CloudSat data are available from http://cloudsat. atmos.colostate.edu/data.

Author contributions. The authors designed the study and prepared the manuscript together. $\mathrm{LN}$ and $\mathrm{AD}$ performed the data analyses.

Competing interests. The authors declare that they have no conflict of interest.

Acknowledgements. The contributions of Tristan S. L'Ecuyer were supported under National Science Foundation grant 1531690.

Edited by: Brian Kahn

Reviewed by: three anonymous referees

\section{References}

Battan, L. J.: Radar observation of the atmosphere, University of Chicago Press, 1973.

Bech, J., Codina, B., Lorente, J., and Bebbington, D.: The sensitivity of single polarization weather radar beam blockage correction to variability in the vertical refractivity gradient, J. Atmos. Ocean. Tech., 20, 845-855, https://doi.org/10.1175/15200426(2003)020<0845:TSOSPW>2.0.CO;2, 2003.

Berrisford, P., Dee, D., Poli, P., Brugge, R., Fielding, K., Fuentes, M., Kållberg, P., Kobayashi, S., Uppala, S., and Simmons, A.: The ERA-Interim archive, Era report series, European Centre for Medium Range Weather Forecasts, 2009.

Busuioc, A., Chen, D., and Hellström, C.: Temporal and spatial variability of precipitation in Sweden and its link with the large-scale atmospheric circulation, Tellus A, 53, 348-367, https://doi.org/10.1034/j.1600-0870.2001.01152.x, 2001.

Carlsson, I.: NORDRAD - weather radar network, in: COST 75 Weather Radar Systems, edited by: Collier, C. G., European Commission, 45-52, 1995.

Chahine, M., Pagano, T., Aumann, H., Atlas, R., Barnet, C., Blaisdell, J., Chen, L., Divakarla, M., Fetzer, E., Goldberg, M., Gautier, C., Granger, S., Hannon, S., Irion, F., Kakar, R., Kalnay, E., Lambrigtsen, B., Lee, S., Marshall, J. L., McMillan, W., McMillin, L., Olsen, E., Revercomb, H., Rosenkranz, P., Smith, W., Staelin, D., Strow, L., Susskind, J., Tobin, D., Wolf, W., and Zhou, L.: AIRS: Improving Weather Forecasting and Providing New Data on Greenhouse Gases, B. Am. Meteorol. Soc., 87, 911-926, https://doi.org/10.1175/BAMS-87-7-911, 2006. 
Chen, D.: A monthly circulation climatology for Sweden and its application to a winter temperature case study, Int. J. Climatol., 20, 1067-1076, https://doi.org/10.1002/10970088(200008)20:10<1067::AID-JOC528>3.0.CO;2-Q, 2000.

Daley, R.: Atmospheric Data Analysis, Cambridge Atmospheric and Space Science Series, Cambridge University Press, 2nd Edn., 1993.

Dee, D. P., Uppala, S. M., Simmons, A. J., Berrisford, P., Poli, P., Kobayashi, S., Andrae, U., Balmaseda, M. A., Balsamo, G., Bauer, P., Bechtold, P., Beljaars, A. C. M., van de Berg, L., Bidlot, J., Bormann, N., Delsol, C., Dragani, R., Fuentes, M., Geer, A. J., Haimberger, L., Healy, S. B., Hersbach, H., Hólm, E. V., Isaksen, L., Kållberg, P., Köhler, M., Matricardi, M., McNally, A. P., Monge-Sanz, B. M., Morcrette, J.-J., Park, B.-K., Peubey, C., de Rosnay, P., Tavolato, C., Thépaut, J.-N., and Vitart, F.: The ERA-Interim reanalysis: configuration and performance of the data assimilation system, Q. J. Roy. Meteor. Soc., 137, 553-597, https://doi.org/10.1002/qj.828, 2011.

Devasthale, A. and Norin, L.: The large-scale spatio-temporal variability of precipitation over Sweden observed from the weather radar network, Atmos. Meas. Tech., 7, 1605-1617, https://doi.org/10.5194/amt-7-1605-2014, 2014.

Devasthale, A., Sedlar, J., Kahn, B., Tjernström, M., Fetzer, E., Tian, B., Teixeira, J., and Pagano, T.: A Decade of Spaceborne Observations of the Arctic Atmosphere: Novel Insights from NASA's AIRS Instrument, B. Am. Meteorol. Soc., 97, 21632176, https://doi.org/10.1175/BAMS-D-14-00202.1, 2016.

Gustafsson, M., Rayner, D., and Chen, D.: Extreme rainfall events in southern Sweden: where does the moisture come from?, Tellus A, 62, 605-616, https://doi.org/10.1111/j.16000870.2010.00456.x, 2010.

Häggmark, L., Ivarsson, K.-I., and Olofsson, P.-O.: MESAN - mesoskalig analys, Reports Meteorology and Climatology RMK 75, SMHI, 1997 (in Swedish).

Häggmark, L., Ivarsson, K.-I., Gollvik, S., and Olofsson, P.-O.: Mesan, an operational mesoscale analysis system, Tellus A, 52, 2-20, https://doi.org/10.1034/j.1600-0870.2000.520102.x, 2000.

Harpold, A. A., Kaplan, M. L., Klos, P. Z., Link, T., McNamara, J. P., Rajagopal, S., Schumer, R., and Steele, C. M.: Rain or snow: hydrologic processes, observations, prediction, and research needs, Hydrol. Earth Syst. Sci., 21, 1-22, https://doi.org/10.5194/hess-21-1-2017, 2017.

Haynes, J. M., L'Ecuyer, T. S., Stephens, G. L., Miller, S. D., Mitrescu, C., Wood, N. B., and Tanelli, S.: Rainfall retrieval over the ocean with spaceborne W-band radar, J. Geophys. Res.Atmos., 114, D00A22, https://doi.org/10.1029/2008JD009973, 2009.

Hellström, C.: Atmospheric conditions during extreme and nonextreme precipitation events in Sweden, Int. J. Climatol., 25, 631-648, https://doi.org/10.1002/joc.1119, 2005.

Johansson, B. and Chen, D.: The influence of wind and topography on precipitation distribution in Sweden: statistical analysis and modelling, Int. J. Climatol., 23, 1523-1535, https://doi.org/10.1002/joc.951, 2003.

Källén, E.: HIRLAM Documentation Manual: System 2.5, Swedish Meteorological and Hydrological Institute, 1996.

Kulie, M. S., Milani, L., Wood, N. B., Tushaus, S. A., and L'Ecuyer, T. S.: A Shallow Snowfall Census Using Spaceborne Radar, J.
Hydrometeorol., 17, 1261-1279, https://doi.org/10.1175/JHMD-15-0123.1, 2016.

Levizzani, V., Laviola, S., and Cattani, E.: Detection and measurement of snowfall from space, Remote Sens.-Basel, 3, 145-166, https://doi.org/10.3390/rs3010145, 2011.

Linderson, M.-L.: Objective classification of atmospheric circulation over southern Scandinavia, Int. J. Climatol., 21, 155-169, https://doi.org/10.1002/joc.604, 2001.

McIlhattan, E. A., L'Ecuyer, T. S., and Miller, N. B.: Observational Evidence Linking Arctic Supercooled Liquid Cloud Biases in CESM to Snowfall Processes, J. Climate, 30, 4477-4495, https://doi.org/10.1175/JCLI-D-16-0666.1, 2017.

Michelson, D.: The Swedish weather radar production chain, in: Proceedings of the Fourth European Conference on Radar in Meteorology and Hydrology, Barcelona, Spain, ERAD, 382-385, 2006.

Michelson, D. B. and Koistinen, J.: Gauge-Radar network adjustment for the Baltic sea experiment, Phys. Chem. Earth Pt. B, 25, 915-920, https://doi.org/10.1016/S1464-1909(00)001258, 2000.

NOAA: http://www.cpc.ncep.noaa.gov/products/precip/CWlink/ pna/nao.shtml, (last access: 16 January 2017), 2016.

Norin, L., Devasthale, A., L'Ecuyer, T. S., Wood, N. B., and Smalley, M.: Intercomparison of snowfall estimates derived from the CloudSat Cloud Profiling Radar and the ground-based weather radar network over Sweden, Atmos. Meas. Tech., 8, 5009-5021, https://doi.org/10.5194/amt-8-5009-2015, 2015.

Smalley, M., L'Ecuyer, T., Lebsock, M., and Haynes, J.: A comparison of precipitation occurrence from the NCEP Stage IV QPE product and the CloudSat Cloud Profiling Radar, J. Hydrometeorol., 15, 444-458, https://doi.org/10.1175/JHM-D-13-048.1, 2014.

Susskind, J., Blaisdell, J. M., and Iredell, L.: Improved methodology for surface and atmospheric soundings, error estimates and quality control procedures: the atmospheric infrared sounder science team version-6 retrieval algorithm, J. Appl. Remote Sens., 8, 084994, https://doi.org/10.1117/1.JRS.8.084994, 2014.

Thomas, M. A. and Devasthale, A.: Sensitivity of free tropospheric carbon monoxide to atmospheric weather states and their persistency: an observational assessment over the Nordic countries, Atmos. Chem. Phys., 14, 11545-11555, https://doi.org/10.5194/acp-14-11545-2014, 2014.

Waliser, D. E., Li, J.-L. F., L'Ecuyer, T. S., and Chen, W.-T.: The impact of precipitating ice and snow on the radiation balance in global climate models, Geophys. Res. Lett., 38, L06802, https://doi.org/10.1029/2010GL046478, 2011.

Wood, N. B.: Estimation of snow microphysical properties with application to millimeter-wavelength radar retrievals for snowfall rate, Ph.D. thesis, Colorado State University, Fort Collins, Colorado, http://hdl.handle.net/10217/48170 (last access: 1 September 2017), 2011.

Wood, N. B., L'Ecuyer, T., Vane, D. G., Stephens, G. L., and Partain, P.: Level $2 \mathrm{C}$ snow profile process description and interface control document, Tech. rep., Colorado State University, http: //www.cloudsat.cira.colostate.edu/sites/default/files/products/ files/2C-SNOW-PROFILE_PDICD.P_R04.20130210.pdf (last access: 1 September 2017), 2013. 
Wood, N. B., L'Ecuyer, T. S., Heymsfield, A. J., and Stephens, G. L.: Microphysical constraints on millimeter-wavelength scattering properties of snow particles, J. Appl. Meteorol. Clim., 54, 909-931, https://doi.org/10.1175/JAMC-D-14-0137.1, 2015. 